\title{
The myb-related gene stonewall induces both hyperplasia and cell death in Drosophila: rescue of fly lethality by coexpression of apoptosis inducers
}

\author{
S Brun ${ }^{1,2}$, A Rincheval-Arnold ${ }^{1,2}$, J Colin ${ }^{1,2}$, Y Risler ${ }^{1,2}$, \\ B Mignotte ${ }^{1,2}$ and I Guénal ${ }^{*, 1,2}$ \\ ${ }^{1}$ Laboratoire de Génétique et Biologie Cellulaire, CNRS MR 8159, Université de \\ Versailles-St. Quentin en Yvelines, 45 avenue des Etats-Unis, F-78035 \\ Versailles cedex, France \\ ${ }^{2}$ Laboratoire de Génétique Moléculaire et Physiologique de l'EPHE, Université \\ de Versailles-St. Quentin en Yvelines, 45 avenue des Etats-Unis, F-78035 \\ Versailles cedex, France \\ * Corresponding author: I Guénal, Laboratoire de Génétique et Biologie \\ Cellulaire, CNRS MR 8159, Université de Versailles-St Quentin en Yvelines, \\ 45 avenue des Etats-Unis, F-78035 Versailles cedex, France. \\ Tel: + 331392536 52; Fax: + 331392536 55; \\ E-mail: guenal@genetique.uvsq.fr
}

Received 21.02.05; revised 24.11.05; accepted 13.12.05; published online 03.2.06 Edited by E Baehrecke

\section{Abstract \\ We carried out gain-of-function mutagenesis screening and identified a mutant in which GAL4 induction led to both hyperplasia and apoptosis. The gene involved was identified as stonewall (stw), a myb-related gene involved in germ cell proliferation and differentiation during oogenesis. As observed with dmyb, the ectopic expression of stw/ ${ }^{\text {UY823 }}$ inhibited endoreplication in salivary glands. We also found that $\left.s t w\right|^{U Y 823}$ overexpression, like overexpression of the wild- type gene, activated G1/S transition and apoptosis. The apoptosis triggered by $s t w l^{U Y 823}$ expression is correlated to induction of the proapoptotic gene reaper. Finally, the death of flies induced by ectopic stw/ ${ }^{U Y 823}$ expression is efficiently prevented in vivo by triggering cell death in stwl ${ }^{\text {YY823. }}$ expressing cells. Our results suggest that $s$ ww $^{\text {UY823 }}$ kills flies by causing inappropriate cell cycle entry, and that triggering the death of these overproliferating cells or slowing their proliferation restores viability. \\ Cell Death and Differentiation (2006) 13, 1752-1762. doi:10.1038/sj.cdd.4401861; published online 3 February 2006}

Keywords: stonewall; myb; rpr, cell proliferation; cell cycle; apoptosis

Abbreviations: $A O$, acridine orange; Brat gene, brain tumor gene; BrdU, bromodeoxyuridine; CDS, coding DNA sequence; CyO, curly of Oster; da, daughterless; Dpp, decapentaplegic; en, engrailed; $f k h$, fork head; GFP, green fluorescent protein; gmr, glass-mediated response; GUS, gmr UAS; hid, head involution defective; Hs, heat shock; hsp70, heat-shock protein 70; ORF, open reading frame; PBS, phosphate-buffered saline; PCD, programmed cell death; rpr, reaper; Sev, sevenless; stwl, stonewall; UAS, upstream activating sequences; $v g$, vestigial; $\mathrm{yw}^{\mathrm{c}}$, yellow white $\mathrm{C} ; \mathrm{ZNC}$, zone of nonproliferating cells

\section{Introduction}

The coordination of cell growth, division and death is essential for normal development and adult survival. Cell growth and division are usually coordinated, leading to cell proliferation and the growth of tissues due to increases in cell number. Endoreplicating tissues are a notable exception, growing partly by means of DNA replication without cell division (review: Edgar and Orr-Weaver ${ }^{1}$ ). Data for mammals and Drosophila show that mechanisms regulating cell proliferation and apoptosis are intimately linked (review: Hipfner and Cohen and Abrams and White ${ }^{2,3}$ ). Neoplasia involves many processes, but the cooperative deregulation of cell proliferation and inhibition of cell death occurs in almost all cases of cancer progression. Indeed, many genes implicated in tumorigenesis act on cell proliferation and/or apoptosis. Some, such as myc and e2f, activate both processes. Consequently, proliferating cells are more susceptible to death signals. In many cases, the inactivation of proapoptotic tumor suppressors, such as $p 53$, is associated with oncogene activation in tumorigenic transformation.

The Drosophila genome sequencing project has shown that most mammalian genes involved in proliferation or apoptosis have a counterpart in flies. This is true for genes involved in cell death execution, such as those encoding caspases, dark (the homolog of apaf-1) and two bcl-2 homologs, debcl and buffy. However, although mammalian Bcl-2 and Bax are functional in vivo in Drosophila, ${ }^{4,5}$ the release of mitochondrial proteins observed in mammalian cell apoptosis is not demonstrated during Drosophila cell death. Genetic approaches have also resulted in the discovery of new apoptosis executors in Drosophila. The products of these genes (Rpr, Hid, Grim, Sickle and Jafrac2) act through binding to inhibitor of apoptosis proteins (IAPs), disrupting caspase inhibition. ${ }^{6}$ Their action on IAPs is similar to that of mammalian Smac/ Diablo and Omi/HtrA2, but, unlike these proteins, Rpr, Hid, Grim and Sickle act upstream from or independently of mitochondria (reviewed in Mignotte et al. ${ }^{7}$ ). Drosophila also has a p53 homolog: Dmp53. ${ }^{8}$ Dmp53, like mammalian p53, is required for apoptosis induced by radiation ${ }^{9}$ or reactive oxygen species, ${ }^{10}$ but, unlike mammalian $p 53$, is not involved in the cell cycle arrest observed after irradiation. ${ }^{11}$

Some of the Drosophila genes involved in cell proliferation and cell death regulation are homologs of known mammalian oncogenes. Those promoting proliferation may inhibit apoptosis. For example, the Drosophila homolog of ras stimulates cell growth and proliferation ${ }^{12}$ whereas it downregulates head involution defective (hid), thereby activating a survival signaling pathway. ${ }^{13}$ Genetic and genomic tools for Drosophila recently led to the discovery of micro RNAs regulating apoptosis and cell proliferation (review: Baehrecke ${ }^{14}$ ). One of these micro RNAs, bantam, stimulates proliferation by driving G1/S and G2/M transitions and inhibiting apoptosis. 
Conversely, as in mammals, many other genes stimulate both proliferation and apoptosis. This is the case for de2f1, the homolog of $E 2 F 1^{15}$ and for the Drosophila Src-family kinases, ${ }^{16}$ which have been shown to enhance proliferation and apoptosis. Slik, which encodes a Ste20 serine/threonine kinase, behaves similarly but also triggers apoptosis when it is downregulated. ${ }^{17}$ Similarly, $d m y b$, the single fly homolog of the vertebrate myb gene family, not only abolishes endoreplication but also promotes proliferation and apoptosis. ${ }^{18}$ C-myc induces both proliferation and apoptosis, and it has been shown that, in Drosophila, Dmyc induces cell competition, leading to the death of surrounding normal cells (review: Secombe et al. ${ }^{19}$ ).

Genes negatively regulating the cell cycle and controlling apoptosis have also been found in Drosophila (review: Sutcliffe et $a l^{20}$ ). Indeed, a pRB network operates in Drosophila. The fly RBF1 - like pRB, which can either inhibit apoptosis through its E2F-inactivating properties (reviewed in Harbour and Dean ${ }^{21}$ ) or enhance cell death ${ }^{22,23}$ through E2Findependent mechanisms ${ }^{24}$ - can inhibit G1/S transition by inhibiting E2F factors and either inhibit or enhance apoptosis, depending on the tissue (Rincheval et al., unpublished data).

Screens for Drosophila loss-of-function mutations resulting in tissue overgrowth have led to the discovery of three genes promoting both cell cycle exit and cell death. The hippo, warts and salvador genes function together to restrict tissue growth in vivo by favoring cell cycle exit and inducing cell death (reviewed in Hay et al. and Mignotte et al. ${ }^{6,7}$ ). This control over programmed cell death (PCD) is achieved by decreases in cell DIAP1 content and the induction of hid expression.

We report here the results of the screening of a gain-offunction mutagenesis involving the transposition of a $\mathrm{P}$ element containing upstream activating sequence (UAS) sequences, $P\left\{\right.$ Mae-UAS.6.11\} ${ }^{25}$ Genes located downstream from the transposon insertion site should therefore be transcriptionally regulated by the UAS/GAL4 system. We characterized one mutant that behaves as a gain-of-function mutation upon GAL4 induction and as a loss-of-function mutation in the absence of GAL4 induction. Depending on the conditions used, this mutant either induces hyperplasia and apoptosis or leads to the death of flies upon GAL4 induction. We also show that the death of the fly can be prevented by triggering cell death, providing evidence that the lethality of this mutant results from hyperproliferation. Finally, we show that these effects result from the deregulation of stonewall (stw). This gene, predominantly expressed in the ovary, has been shown to encode a nuclear protein required for germline cell proliferation and differentiation. ${ }^{26,27}$ The work presented here provides clues to the mechanism of action of stwl.

\section{Results}

\section{GAL4-induced UY823 expression leads to adult phenotypes reminiscent of cell death and cell proliferation}

We carried out gain-of-function mutagenesis screening, with the aim of identifying new regulators of apoptosis. We used $P\{$ Mae-UAS.6.11\} (abbreviated in UY), a $\mathrm{P}$ element vector containing UAS sequences. Genes downstream from the transposon insertion site should be transcriptionally regulated by the UAS/GAL4 system. The UY823 transgenic line displayed an interesting phenotype. Specific GAL4 induction in the ventral lateral neurons of UY823 adults, driven by $G A L 1118,{ }^{28}$ led to cell death (E Blanchardon and F Rouyer, personal communication). We studied the effects of UY823 induction in various tissues during development, using several drivers (glass-mediated response (gmr)-GAL4, daughterless (da)-GAL4, engrailed (en)-GAL4, heat-shock ( $h s)-G A L 4$ and vestigial $(v g)-G A L 4)$. Transcriptional regulation of the gene next to the UYP element in the UY823 line by GAL4 throughout development impaired viability (Table 1). This effect increased with the temperature, consistent with the increase in efficiency of the GAL4 system. Drosophila eyes consist of ommatidia precisely positioned within a highly ordered crystalline lattice; they have been widely used to study the effects of apoptosis regulators. We found that specific UY823 induction in the eye during development by the $g m r-G A L 4$ driver at $21^{\circ} \mathrm{C}$ (Figure $1 \mathrm{a}$ and b) led to the development of small, rough, less pigmented eyes. Moreover, GAL4 induction of UY823 by the vg-GAL4 driver at a sublethal temperature $\left(21^{\circ} \mathrm{C}\right)$ induced the formation of notches at the wing margin (Figure 1d). All of these phenotypes may result from excess cell death. However, the vg-GAL4 induction of UY823 also led to prominent hyperplastic buds on the wing hinge (Figure 1d). Furthermore, UY823 induction by the en-GAL4 driver in the posterior compartment of the wing disc induced hyperplastic tissues in the posterior part of the wing (data not shown). The induction of UY823 in the wing therefore demonstrates that the gene located downstream from the UAS sequences can induce both cell death and proliferation.

Table 1 Percentage viability and phenotypes induced by GAL4 expression in UY823

\begin{tabular}{|c|c|c|c|c|c|c|}
\hline & \multicolumn{2}{|c|}{$18^{\circ} \mathrm{C}$} & \multicolumn{2}{|c|}{$21^{\circ} \mathrm{C}$} & \multicolumn{2}{|c|}{$25^{\circ} \mathrm{C}$} \\
\hline & Viability & Adult phenotype & Viability & Adult phenotype & Viability & Adult phenotype \\
\hline $\begin{array}{l}\text { en }>U Y 823 \\
v g>U Y 823 \\
g m r>U Y 823 \\
\text { da }>U Y 823 \\
h s>U Y 823\end{array}$ & $\begin{array}{l}25.6 \%\left(N_{\mathrm{TM} 3}=69\right) \\
76.4 \%\left(N_{\mathrm{TM} 3}=146\right) \\
81.4 \%\left(N_{\mathrm{TM} 3}=34\right) \\
82.1 \%\left(N_{\mathrm{TM} 3}=59\right) \\
\text { ND }\end{array}$ & $\begin{array}{l}\text { Notches wing hairs } \\
\text { Notches } \\
\text { Rough eye } \\
\text { No } \\
\text { ND }\end{array}$ & $\begin{array}{l}<0.6 \%\left(N_{\mathrm{TM} 3}=132\right) \\
30.5 \%\left(N_{\mathrm{TM}}=116\right) \\
7.5 \%\left(N_{\mathrm{TM}}=51\right) \\
50.3 \%\left(N_{\mathrm{TM} 3}=130\right) \\
\text { ND }\end{array}$ & $\begin{array}{l}\text { Lethality } \\
\text { Notches hyperplasia } \\
\text { Glass eye } \\
\text { No } \\
\text { ND }\end{array}$ & $\begin{array}{l}<0.7 \%\left(N_{\mathrm{TM} 3}=106\right) \\
<0.1 \%\left(N_{\mathrm{TM} 3}=531\right) \\
<1.4 \%\left(N_{\mathrm{TM} 3}=53\right) \\
<0.6 \%\left(N_{\mathrm{TM} 3}=122\right) \\
8.1 \%\left(N_{\mathrm{TM} 3}=448\right)\end{array}$ & $\begin{array}{l}\text { Lethality } \\
\text { Lethality } \\
\text { Lethality } \\
\text { Lethality } \\
\text { No }\end{array}$ \\
\hline
\end{tabular}

Percentage viability $=\left(N_{\text {UY823/ }} /\left(1.3 \times N_{\text {TM3 }}\right)\right) \times 100$; when no $U Y 823 /+$ flies are born in the progeny, the percentage viability $<\left(1 /\left(1.3 \times N_{\mathrm{TM} 3}\right)\right) \times 100$. ND: not determined. no: no phenotype observed 

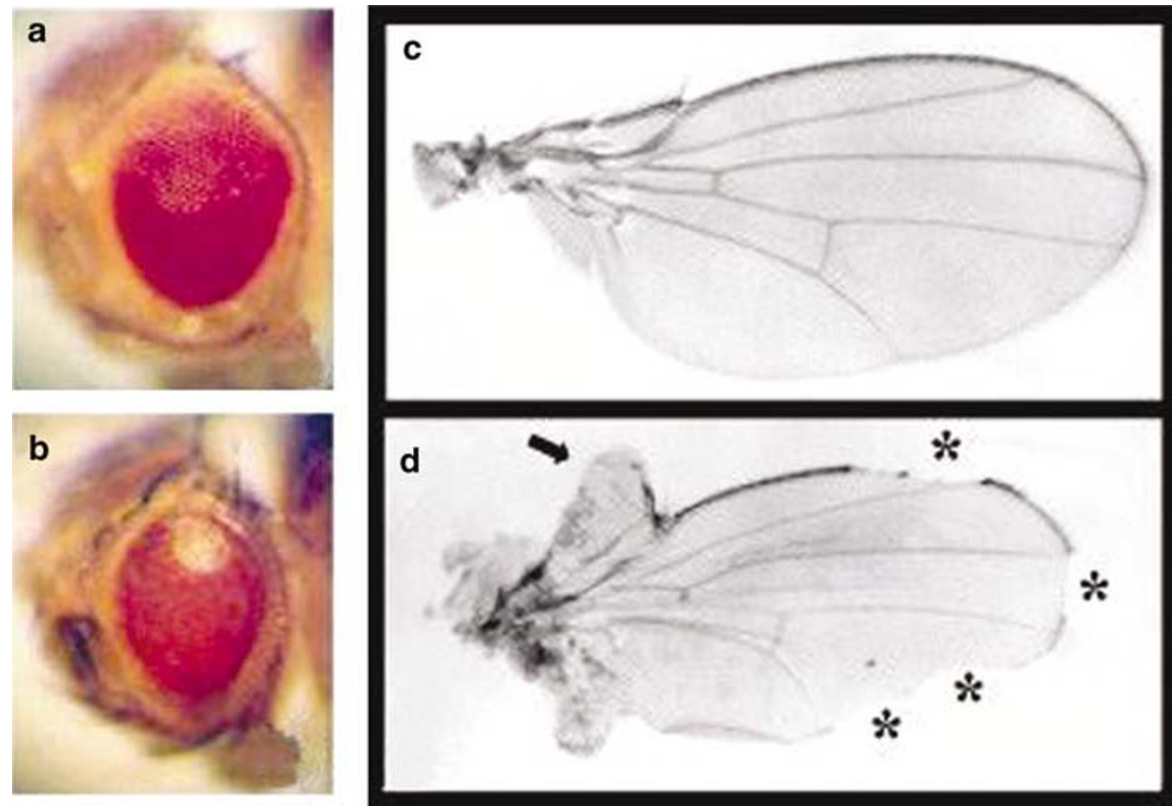

Figure 1 Induction of UY823 triggers adult phenotypes reminiscent of cell death and cell proliferation. (a, b) Photographs of Drosophila eye and (c, d) wings mounted in Mowiol. The figure compares the phenotype associated with GAL4 induction in UY823 Drosophila eye (b, gmr $>$ UY823) and wing (d, vg $>$ UY823), with that of control eye (a, gmr-GAL4/+) and wing (c, vg-GAL4/+). Less pigmented glassy eyes are observed in (b). Arrows indicate hyperplastic buds and stars indicate wing notches. Flies were raised at $21^{\circ} \mathrm{C}$
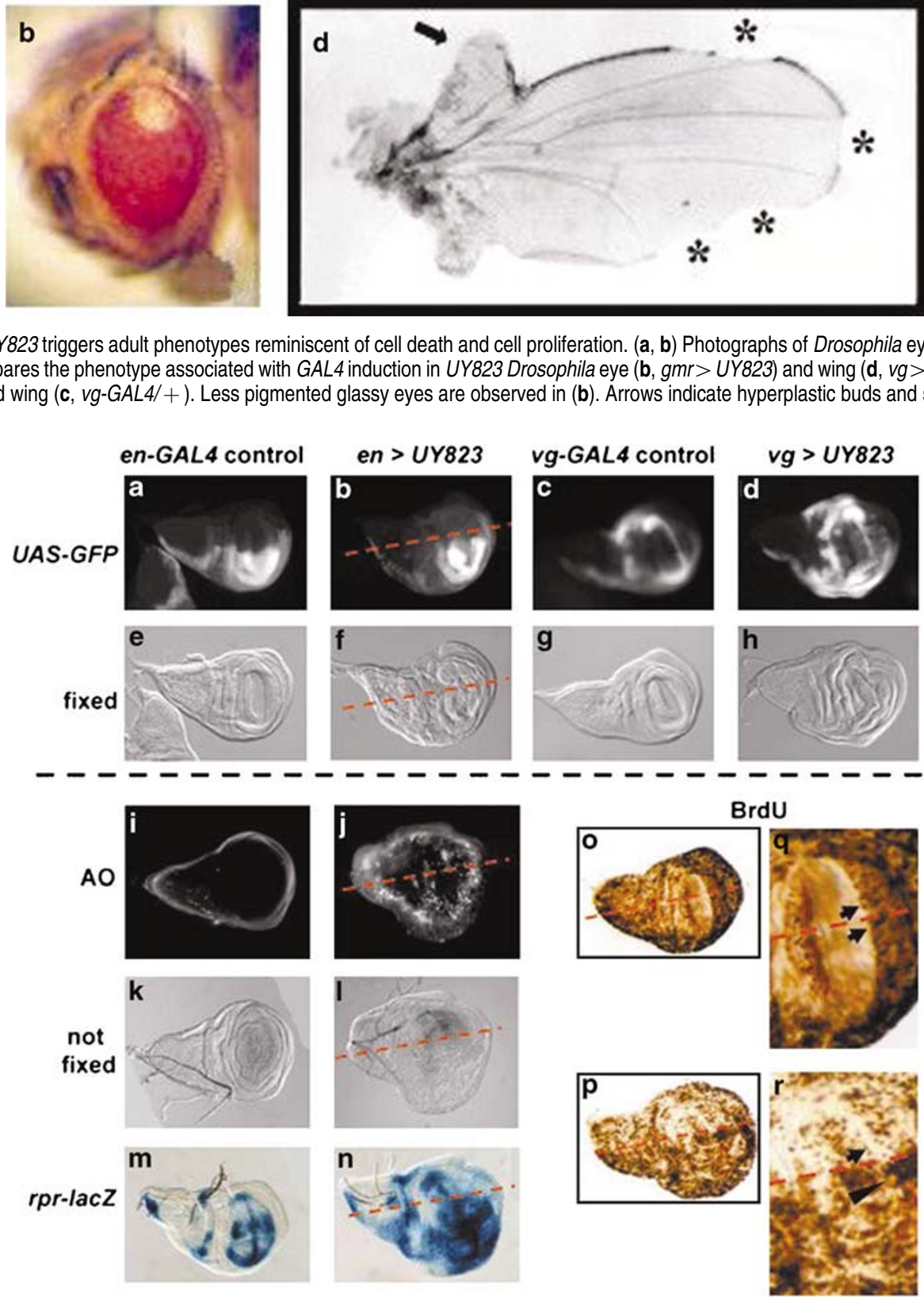

Figure 2 Induction of UY823 triggers hyperproliferation and apoptosis in third instar larval wing discs. The first and third columns correspond to control discs for enGAL4 and vg-GAL4 induction, respectively. The second and last columns correspond to wing discs with en-GAL4 and vg-GAL4 induction, respectively, in UY823 lines. All discs are shown with the anterior at the top and the posterior at the bottom. The A-P boundary is outlined by a red dotted line. Fluorescence micrographs of fixed discs expressing UAS-GFP under en-GAL4 induction (a, b) and under vg-GAL4 induction (c, d) are shown. (e-h) Corresponding Nomarski micrographs of discs (a-d). (i,j) AO staining of unfixed discs and their corresponding Nomarski images (k, I). X-gal staining of control en-GAL4/+;rpr-11-lacZ/ + fixed discs (m) and of en-GAL4/+;rpr-11lacZ, UY823/+ fixed discs (n). BrdU incorporation in en-GAL4/+ control fixed discs at low and high magnifications (o, q) and in fixed discs en-GAL4/+; UY823/+ at low and high magnifications $(\mathbf{p}, \mathbf{r})$. Arrows indicate the ZNC, and an arrowhead indicates the absence of ZNC in the posterior region of the en-GAL4/+; UY823/+ wing disc 


\section{Induction of UY823 in the wing discs triggers hyperproliferation by activating entry into $S$ phase}

We studied the effect of UY823 insertion on proliferation during development, using the en-GAL4 and vg-GAL4 drivers to induce UY823 in wing discs. The pattern of expression of these two drivers in the wing disc is clearly illustrated by green fluorescent protein (GFP) expression in Figure 2a and c.

The en $>U Y 823$ and $v g>U Y 823$ discs showed massive hyperplasia (Figure 2). Indeed, the posterior part of the en $>U Y 823$ discs was much larger than the posterior part of the control discs (compare Figure $2 \mathrm{f}-\mathrm{e}$ and $\mathrm{l}-\mathrm{k}$ ). Similarly, the hinge and wing pouch of $v g>U Y 823$ fixed discs were formed with prominent, multiple folds, resulting from an excess of cells (Figure $2 \mathrm{~h}-\mathrm{g}$ ). In the wing discs, cell proliferation occurred throughout larval development, in the entire disc. At the third instar stage, margin cells (in the wing pouch) were blocked in G1, generating a zone of nonproliferating cells (ZNC - see arrows in Figure $2 q$ and $r$ ). As observed in control discs (Figure 20 and $\mathrm{q}$ ), S-phase cells were labeled with bromodeoxyuridine (BrdU) throughout the disc, with the exception of the ZNC. BrdU labeling in en>UY823 discs was clearly stronger in the hypertrophied posterior part than in the anterior part, demonstrating that UY823 expression induced an increase in the number of cells in $S$ phase (Figure $2 p$ and $r$ ). Moreover, unlike ZNC cells in the anterior part of the en $>$ UY823 wing pouch, the cells located in the posterior part of the wing disc pouch were labeled with BrdU. This suggests that cells of the ZNC subjected to UY823 induction overcome the normal G1/S block. Thus, deregulation of the gene next to UY823 insertion triggers cell proliferation, at least by activating the entry of cells into $S$ phase.

\section{UY823 induction in wing discs causes apoptosis and is correlated with induction of the proapoptotic gene rpr}

We studied the capacity of the gene next to UY823 insertion to trigger apoptosis, using a specific marker, acridine orange (AO), to visualize apoptosis in vivo in induced UY823 tissues. In control wing discs, only a few cells died by apoptosis, as shown by $A O$ staining (Figure 2i). By contrast, massive $A O$ staining was observed in the posterior part of en $>U Y 823$ third instar larval wing discs (Figure 2j), corresponding to the area of en-GAL4 driver expression. Slightly stronger AO staining was also observed in the anterior region of the disc, suggesting that some compensation occurs in this area.

In Drosophila, the proapoptotic gene reaper $(r p r)$ is transcriptionally induced to trigger apoptosis during embryonic development, metamorphosis and after X-ray irradiation. ${ }^{29}$ We investigated whether UY823 induction activated rpr transcription, by comparing the staining pattern of en-GAL4/ + ;rpr-11-lacZ,UY823/+ discs with that of en-GAL4/+;rpr11-lacZ/+ control discs, using the rpr-11-lacZ construct. ${ }^{30}$ In control discs, in situ X-gal staining showed that rprexpression was prominent in the wing hinge and wing pouch, where it occurred in the margin (dorso-ventral limit) and perpendicularly, at the antero-posterior limit (Figure 2m). Patches of $r p r$ expression were also observed in the wing attach and at the tip of the notum. In en $>U Y 823$ discs, UY823 induction in the
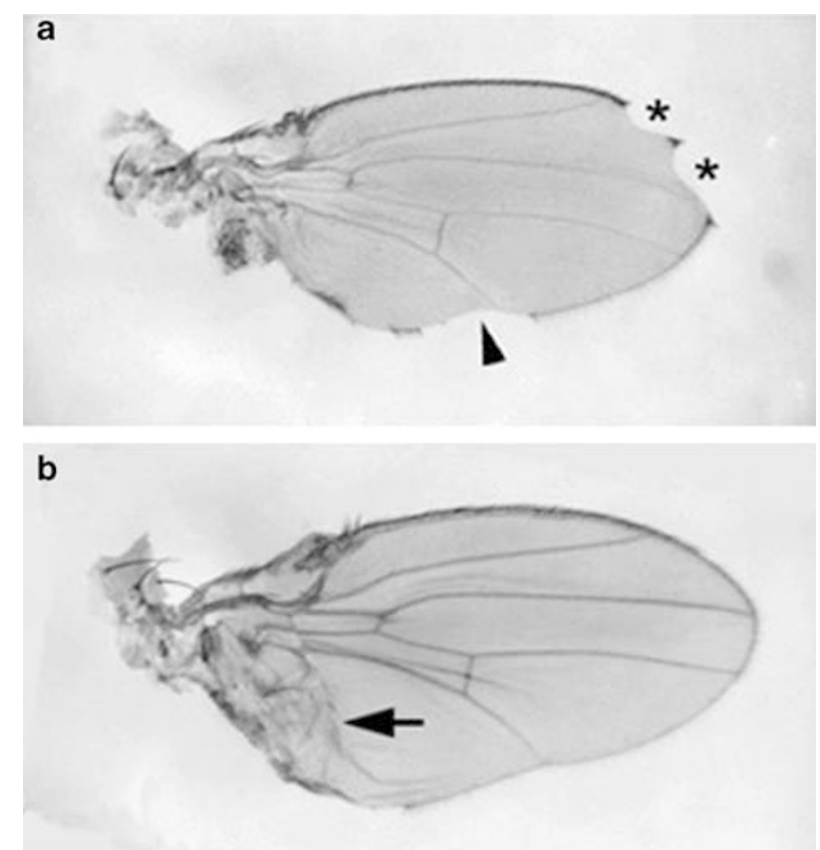

Figure 3 Coexpression of the p35 partially suppresses the wing phenotype of vg $>$ UY823 flies. (a, b) Wings of vg-GAL4, UAS-GFP/+; UY823/+ and UASP35/+; vg- GAL4, UAS-GFP/+; UY823/+ flies, respectively. Asterisks indicate notches in the anterior part of the wing and an arrowhead shows notch in the posterior part of the wing. An arrows indicates the presence of extra tissue folds in the hinge region of the wing. Flies were raised at $21^{\circ} \mathrm{C}$

posterior part of the disc was associated with an increase in rpr expression (Figure 2n). In addition, consistent with AO staining, rpr expression also increased in the anterior part of the disc, but to a lesser extent. These results clearly show that deregulation of the gene next to UY823 insertion directly or indirectly activated $r p r$ transcription. Rpr-induced apoptosis has been shown to involve IAP inhibition and caspase activation. We investigated whether the wing notch phenotypes observed in $v g>U Y 823$ Drosophila were due to ectopic apoptosis. We did this by abolishing these phenotypes, by coexpressing the caspase inhibitor p35 gene. Flies expressing $p 35$ alone with the $v g$-GAL4 driver at $21^{\circ} \mathrm{C}$ have normal wing sizes and do not display notch phenotypes. At $21^{\circ} \mathrm{C}$, $v g>U Y 823$ flies coexpressing the $p 35$ gene carried fewer notches than $v g>U Y 823$ flies (Figure 3). Indeed, 21 of the 58 $v g>U Y 823$ flies coexpressing the $p 35$ gene had more than two notches, versus 48 of 67 for $v g>U Y 823$ flies $\left(\chi^{2}\right.$ test, $\left.P=7 \times 10^{-5}\right)$. We also found that $v g>U Y 823$ flies had notches in the posterior part of the wing, but also often in the anterior part of the wing (Figure 3a). This may be due to weaker expression of the $\mathrm{vg}$-GAL4 driver in the anterior region of the $v g>U Y 823$ wing disc (Figure 2d). Notches in the anterior part of the wing were rarely observed in the presence of p35 ( $\chi^{2}$ test, $\left.P=1.38 \times 10^{-7}\right)$. These results suggest that the notch phenotype is due to caspase-dependent apoptosis. Furthermore, coexpression of the $p 35$ gene often results in an expansion of the dorsal compartment in the hinge of the wing, consistent with strong $v g$-GAL4 expression in this region (Figure 2d). This expansion is associated with the presence of 
extra tissue folds (Figure 3b), possibly arising from excessive proliferation.

\section{Characterization of the stwl ${ }^{U Y 823}$ allele}

Homozygous females of the UY823 transgenic line are sterile and do not lay eggs. We made use of this property for genetic complementation screening. These mutant females have rudimentary ovaries (depleted of post-vitellogenic eggs), but the germaria are hypertrophied, containing abnormal egg chambers (data not shown). As the P element UY823 is located on the third chromosome, we screened for deletions of this chromosome that do not complement UY823 female sterility. We identified three such deletions: $D f(3 L) f z-D 21$ (70D1-2;70E7), Df(3L)fz-GS1a (70D2;70E4-5) and Df(3L)Brd6 (7OE;71F). We also tested 46 mutations or $\mathrm{P}$ insertions located in the genomic region defined by these deletions. Only $P\{l a c W\}$ stw $^{j 6 C 3}$ (stock BL-12087), an insertion in the stwl gene, failed to complement female sterility, suggesting that $s t w l$ is mutated in the UY823 line. We have named this new allele stwl ${ }^{U Y 823}$ Interestingly, stwl loss of function induced female sterility with phenotypes strikingly similar to those observed in sterile stwl ${ }^{u Y 823}$ females. ${ }^{26}$ We also found that $s t w{ }^{995}$, a null allele of $s t w l$, did not complement female sterility. Finally, we confirmed that the recessive stwl $^{\text {UY823 }}$ mutation was a loss-of-function mutation of stwl by showing that female sterility is rescued by introducing the stwl 'minigene' into the stwl ${ }^{U Y 823}$ genetic background. As expected, $y, w / y, w ; P\left\{w^{+}\right.$, minigene $\left.s t w \mid\right\} /+; s t w l^{U Y 823} /$ $s t w l^{U Y 823}$ females were fertile, laying viable eggs.

\section{Molecular characterization and regulation of stwl ${ }^{\text {U823 }}$ mRNA}

We used a forward primer specific to the $\mathrm{P}$ element $\left(\mathrm{P} 1^{\text {ISA }}\right)$ and a reverse primer complementary to the minus strand of stwl (P2 $\left.{ }^{\text {stwlR3 }}\right)$, for classical PCR amplification of genomic DNA to recover the flanking sequences transcribed upon GAL4 induction. A 2900-base pair (bp) DNA fragment (not shown) was amplified, indicating that the UY823 P element was inserted in the first exon of $s t w l$ and that its orientation was consistent with transcription of the coding strand of stwl $(+$ strand). Analysis of the sequences of two independent PCR products indicated that the UY823 P element was inserted at position +111 in the first exon of stwl and that the ATG in -3 of the P element was in frame with the coding sequence of stwl (Figure 4a). Thus, whereas the open reading frames (ORFs) starting from the two more internal ATGs of the $P$ element encode very short polypeptides

a

UY823

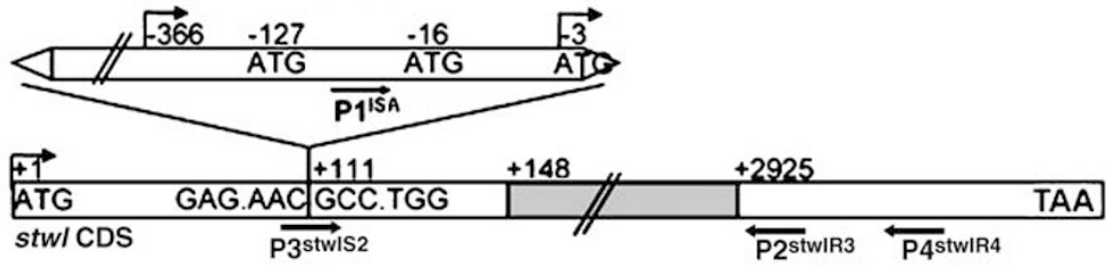

b

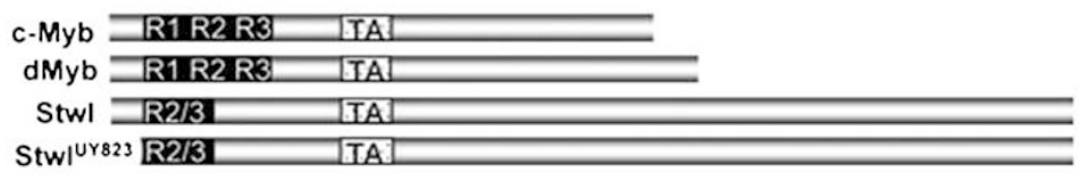

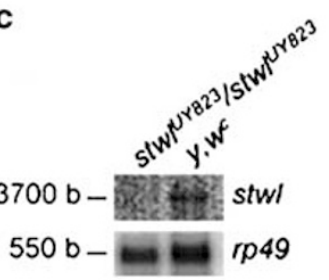

d

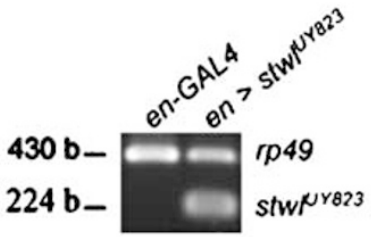

e

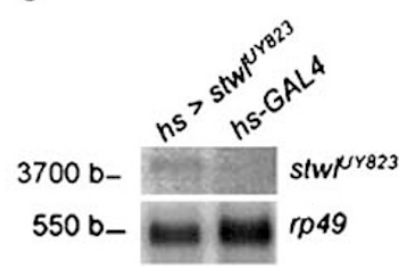

Figure 4 Molecular localization of the UY823 mutation and analysis of stw/ ${ }^{U Y 823}$ expression. (a) Schematic representation of the $5^{\prime}$ end of the UYP element inserted into the coding sequence of stwl. The transcription start site $-366 \mathrm{bp}$ from the end of the $U Y$ transposon and the ATG start codons are indicated by arrows. The primers used for PCR are indicated by arrows. The sole intron of stwl, located from +148 to $+2925 \mathrm{bp}$, is shown in gray. (b) Schematic diagram of Myb family proteins. The Nterminus to the left and the C-terminus is shown to the right. The R1, R2 and R3 repeats of the Myb DNA-binding domain are shown, together with the acidic transactivation domain (TA). The Stwl protein consists of one Myb DNA-binding domain, the R2 and R3 repeats, and a putative acidic transactivation domain. (c) Northern blot analysis of poly $(A)^{+}$mRNA from adult females. The stwl-specific probe demonstrated stwl expression in control flies, whereas no stwl mRNA was

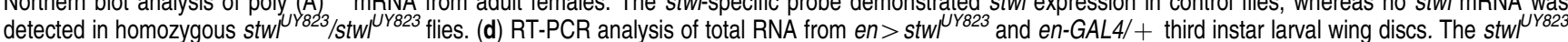
mRNA was amplified using P1 $1^{\text {ISA }}$ and P2 $2^{\text {stwIR3 }}$ primers. The mRNA of stw/ ${ }^{\text {UY } 823}$ was detected in en $>$ stw/ ${ }^{\text {UY823 }}$ discs but not in control discs. (e) Northern blot analysis of adult male total RNA. The stwl-specific probe demonstrated basal constitutive expression of stw/ ${ }^{U Y 823}$ in $h s>s t w /{ }^{U Y 823}$ males, whereas stwl mRNA was not detected in hs-GAL4/+ control males 
( $<30$ amino acids), translation from the ATG in frame with the stwl coding DNA sequence (CDS) would lead to the production of a Stwl protein with the first 37 amino acids deleted. Stwl belongs to the Myb protein family. All the proteins of this family have at least one Myb DNA-binding domain (Figure 4b). This domain corresponds to a sequence of approximately 50 amino acids, containing a series of highly conserved residues, which folds into a helix-turn-helix (HTH) structure. Unlike dMyb, which bears three repeats of the Myb DNA-binding domain, Stwl has a single DNA-binding motif related to the Myb domain. Stwl also bears a putative acid-rich transactivator domain, suggesting its possible involvement of transcriptional regulation. The putative $\mathrm{N}$-terminally truncated Stwl protein induced by GAL4 in stw/ ${ }^{\text {UY823 }}$ flies contained a truncation of the Myb/HTH DNA-binding motif. However, helices 1 and 2 remained intact in this truncated protein (Figure 4b).

Northern blot analysis on poly $(A)+$ mRNA indicated that

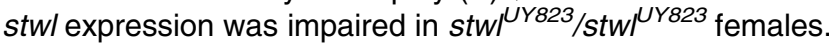
We detected stwl mRNA in control females, but not in sterile stwl $^{\text {UY823/stwl }}{ }^{\text {UY823 }}$ females (Figure 4c). We investigated whether stwl ${ }^{\text {Y823 }}$ transcription was activated upon GAL4 induction by carrying out semiquantitative RT-PCR on total RNA extracted from en $>$ stwl ${ }^{\text {YY823 }}$ wing discs. We detected stwl $^{\text {UY823 }}$ mRNA in en $>$ stwl ${ }^{\text {U823 }}$ larvae, but not in en-GAL4/ + controls (Figure 4d). We also determined the size of the stwl ${ }^{\text {YY823 }}$ mRNA by Northern blot analysis of total RNA extracted from adult $h s>s t w l^{u Y 823}$ flies. The stwl cDNA is 3636 bp long (Genbank Acc Num:U41367) and the ATG start codon is located +161 bases from the beginning of the cDNA. The transcription start site within the UYP element is located -366 from the end of the transposon, giving a predicted size of 3761 bases $(3636-110-161+366)$ for stw/ ${ }^{\text {YY } 823}$ spliced mRNA. The expression of $s t w /{ }^{U Y 823}$ was weak and constitutive in $h s>s t w l^{U Y 823}$ adult flies (Figure 4e). The apparent size of $s t w /{ }^{U Y 823}$ mRNA was about 3700 bases, consistent with the production of a spliced mRNA starting from the transposon transcription start site.

\section{Effects of stwl ${ }^{U 823}$ and full-length stwl expression on apoptosis and cell proliferation are similar}

As stwl deregulation in the UY823 line is driven by UAS sequences upstream from stwl, it is theoretically possible that these UAS drive a neighboring gene other than stwl, possibly accounting for the observed phenotypes. Furthermore, as the putative Stwl ${ }^{\text {UY823 }}$ protein lacks the first 37 amino acids of Stwl, it may exert a dominant-negative effect after ectopic expression. We tried to determine whether one of these possibilities applied, by studying phenotypes associated with the overexpression of full-length stwl in another genetic background. We used a heat-shock protein 70 (hsp70)-stwl line ${ }^{26}$ in which stwl was overexpressed in response to heatshock. We performed AO staining on wing discs from control or hsp70-stwl heat-shocked larvae. Wing discs overexpressing stwl showed stronger AO staining than control discs (Figure $5 \mathrm{c}$ and d), indicating that stwl overexpression causes apoptosis. In BrdU labeling experiments, slightly more stained cells were detected in the ZNC in heat-shocked wild-type
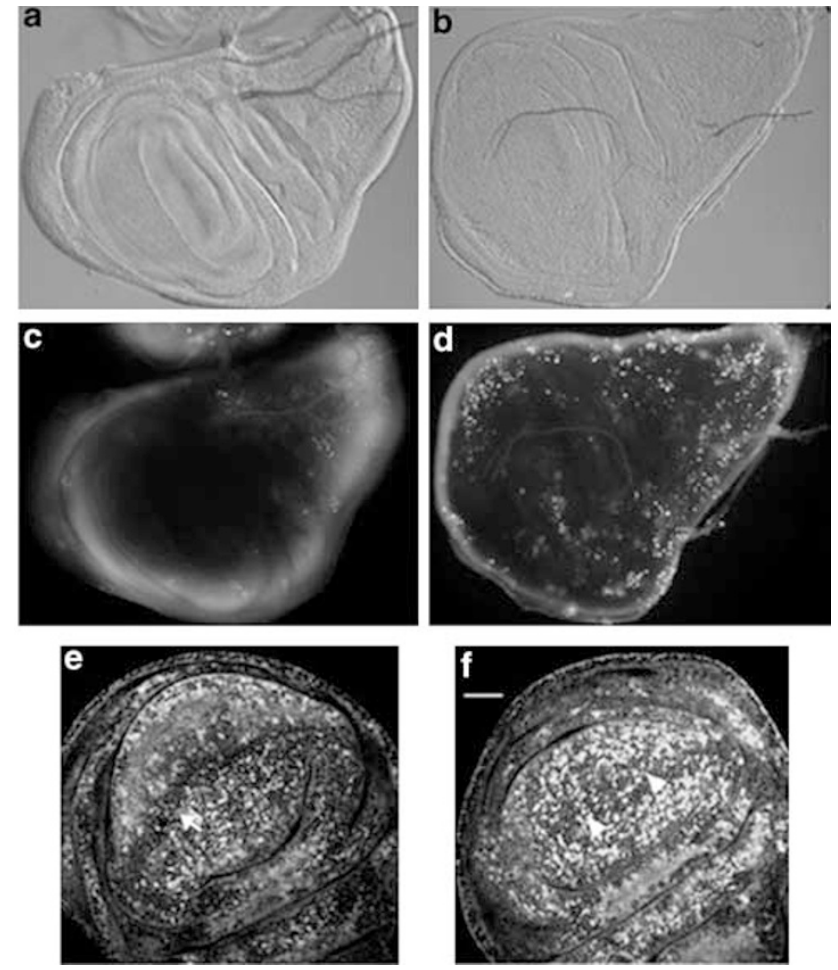

Figure 5 Induction of full-length stwl expression triggers hyperproliferation and apoptosis in third instar larval wing discs. All discs were obtained from heatshocked larvae. The first column corresponds to wild-type discs and the second to hsp70-stwl-expressing discs. (a-d) Discs are shown with the anterior at the top and the posterior at the bottom. (e-f) show a magnification of the wing pouch observed with a confocal microscope. (c, d) AO staining of unfixed discs and their corresponding Nomarski micrographs $(\mathbf{a}, \mathbf{b})$. (e, f) BrdU incorporation in fixed discs. An arrow indicates the ZNC and arrowheads show the presence of stained cells in the ZNC. The scale bar represents $36 \mu \mathrm{m}$

larval discs (Figure 5e) than in non-shocked wild-type larval discs (data not shown), suggesting that heat-shock may have a slight effect on larval cell proliferation. Nevertheless, following the induction of stwl expression by heat shock, BrdU staining increased in the ZNC of the wing pouch (compare Figure 5e and f). This indicates an increase in the number of cells in S phase in the ZNC. Thus, stwl expression induced cell proliferation by activating the entry of cells into $S$ phase. As the hsp70-stwl transgene is located at a site other than the stwl locus, these results show that the data obtained for stw/ ${ }^{4823}$ were the consequence of the overexpression of stwl, rather than of another, neighboring gene.

Heat-shocked hsp70-stwl larvae died soon after induction. We were therefore unable to study the corresponding adult phenotypes. We used the transgenic line $s t w l^{\text {GS3129 }}$ to compare the ectopic expression of full-length stwl with that

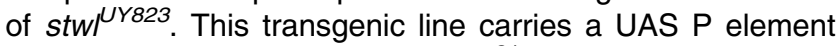
inserted upstream from stwl CDS, ${ }^{31}$ making it possible to express the full-length stwICDS. Using the same drivers as for stwl ${ }^{\text {UY23 }}$ expression, with various breeding temperatures, we obtained viable adults, making it possible to compare phenotypes induced by both forms of Stwl. The expression of stwl ${ }^{\text {GS3129 }}$ in the eye and in the wing during development induces effects reminiscent of cell death, similar to those 
Table 2 Percentage lethality triggered by UY823 induction in embryos, larvae and pupae raised at $25^{\circ} \mathrm{C}$

\begin{tabular}{|c|c|c|c|c|}
\hline$\%$ Lethality & $\begin{array}{c}w^{1118} / y, w^{c} \\
N=250(\%)\end{array}$ & $\begin{array}{c}w^{1118} / y, w^{c} ; \text { UY823/+ } \\
N=256(\%)\end{array}$ & $\begin{array}{c}w^{1118} / y, w^{c} ; v g-G A L 4 /+ \\
N=267(\%)\end{array}$ & $\begin{array}{c}w^{1118} / y, w^{c} ; v g-G A L 4 /+; \\
\text { UY823/+ } N=272(\%)\end{array}$ \\
\hline Embryonic & 3 & 4 & 3 & 1 \\
\hline Larval & 16 & 10 & 15 & 16 \\
\hline Pupal & 1 & 2 & 4 & 83 \\
\hline
\end{tabular}

$N=$ number of fertilized embryos counted

induced by stw/ ${ }^{\text {YY823 }}$ expression. We also demonstrated that $s t w l^{G S 3129}$ induced apoptosis and proliferation at the cellular level. These results are presented in supplementary data.

These results show that stwl activates cellular proliferation and apoptosis and suggest that the N-terminal portion of stwl is not required for the activation of cellular proliferation and apoptosis.

\section{Coexpression of proapoptotic genes prevents the pupal death triggered by stwl ${ }^{\text {Y } 823}$ expression}

The $v g$-GAL4-driven expression of $s^{\prime} l^{\text {UY823 }}$ leads to pupal death at $25^{\circ} \mathrm{C}$ (Table 2). Death may result from excessive cell death or from hyperproliferation. We investigated the possible role of cell death triggered by $s \mathrm{w}^{\text {UY823 }}$ induction in pupal death by coexpressing antiapoptotic genes, such as UAS$q b c l-2, U A S-p 35$ and UAS-diap1. Surprisingly, none of these genes abolished pupal death (data not shown). We studied the contribution of hyperproliferation to pupal death, by investigating whether the coexpression of proapoptotic genes (UAS-bax, UAS-rpr, UAS-hid, UAS-grim, UAS-sickle, UASdronc, UAS-dredd $\delta$ and gmr UAS (GUS)-p53) or antiproliferative genes (UAS-dacapo/p21, UAS-rbf and brain tumor gene $(\text { brat })^{U Y 113}$ ) could prevent pupal death (Table 3 ). Coexpression of all the proapoptotic genes studied here prevented pupal death. The surviving flies presented a strong wing phenotype (Figure 6), with thoracic defects sometimes observed in the survivors coexpressing bax. Furthermore, with the exception of dacapo/p21, the coexpression of antiproliferative genes decreased pupal lethality and the few escapers display also a strong wing phenotype (data not shown). Thus, the abolition of pupal death was not genespecific. Instead, it depended on the elimination of cells decreasing fly viability from tissues. Thus, the $v g$-GAL4-driven induction of stw/ ${ }^{\text {Y } 823}$ probably triggers a high level of cell proliferation, interfering with vital functions during pupariation, and blocking cell proliferation in the tissue or triggering the death of these supernumerary cells may therefore restore viability.

\section{Expression of $s t w l^{U Y 823}$ is associated with endoreplication defects in salivary glands}

Studies on dMyb have shown that the ectopic expression of $d m y b$ inhibits endoreplication ${ }^{18}$ in salivary glands. As Stwl belongs to the dMyb family, we investigated the effects of stw/ ${ }^{\text {Y } 823}$ expression on endoreplication. We carried out Hoechst staining on the DNA of salivary gland cells from control or induced stw/ ${ }^{U Y 823}$ third-instar larvae. We used fork head ( $f k h)-G A L 4$ to drive stw/ ${ }^{\text {Y } 823}$ expression in salivary
Table 3 Percentage viability of flies expressing different transgenes under $v g$ GAL4 control in the UY823 line at $25^{\circ} \mathrm{C}$

\begin{tabular}{lrc}
\hline Co-expressed genes & $\boldsymbol{N}_{\mathbf{U Y 2 3}} / \boldsymbol{N}_{\text {TM3 }}$ & Survival (\%) \\
\hline Control & $0 / 531$ & $<0.1$ \\
UAS-GFP & $0 / 78$ & $<1.0$ \\
UAS-bax & $10 / 7$ & 120.9 \\
UAS-hid & $12 / 11$ & 83.9 \\
UAS-rpr & $20 / 28$ & 71.4 \\
GUS-p53 & $33 / 37$ & 68.6 \\
UAS-grim & $6 / 13$ & 35.5 \\
UAS-sickle & $22 / 48$ & 35.3 \\
UAS-prodronc & $7 / 75$ & 7.2 \\
UAS-dredd $\delta$ & $3 / 49$ & 4.7 \\
UAS-rbf & $5 / 151$ & 2.5 \\
UY1131 (brat) & $2 / 102$ & 1.5 \\
UAS-dacapo & $0 / 81$ & $<0.9$ \\
\hline
\end{tabular}

Percentage viability $=\left(N_{\text {UY823/ } /} /\left(1.3 \times N_{\text {TM } 3}\right)\right) \times 100$; when no UY823/+ are born in the progeny, the percentage of viability $<\left(1 /\left(1.3 \times N_{\text {TM } 3}\right)\right) \times 100$

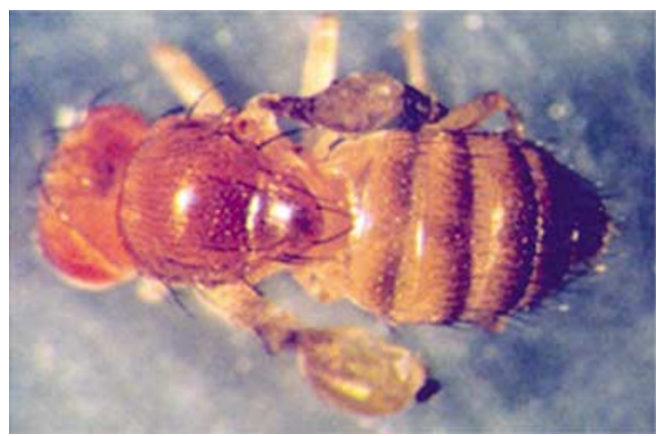

Figure 6 Phenotype of a viable adult $v g>r p r$; UY823 fly raised at $25^{\circ} \mathrm{C}$. The image shows a viable UAS-rpr/Y; vg-GAL4, UAS-GFP/+; stw/ $\left.\right|^{U Y 823} /+$ adult obtained at $25^{\circ} \mathrm{C}$. This survivor had a strong wing phenotype

glands. Cell size is generally proportional to the amount of nuclear DNA and endoreplication is an efficient growth strategy in differentiated tissues. Salivary glands with induced stwl ${ }^{\text {Y823 }}$ were only about one-fifth the size of control glands (Figure $7 \mathrm{a}$ and $\mathrm{f}$ ). These salivary glands are composed of much smaller cells than control glands, as shown by Nomarski imaging (Figure 7b and g). DNA staining of control (Figure 7ce) and induced stwl ${ }^{U Y 823}$ (Figure $7 \mathrm{~h}-\mathrm{j}$ ) salivary gland cells is shown. Mutant salivary gland cell nuclei (Figure $7 \mathrm{~h}$ and $\mathrm{j}$ ) were less strongly stained than control salivary gland cell nuclei (Figure 7c and e), whereas the nuclei of fat body cells were stained equally strongly in the control and the mutant (Figure $7 \mathrm{~d}$ and i). The nuclei of induced stw/ ${ }^{U Y 823}$ salivary glands were also smaller than control nuclei (Figure 7j and e). Thus, mutant salivary gland cell nuclei contain less DNA than control 
salivary gland or fat body cell nuclei, consistent with the lower level of endoreplication in induced stw/ ${ }^{4823}$ flies.

Some nuclei also display changes to chromatin morphology, suggesting that the cells may be dying. However, Hoechst labeling of these nuclei was weaker than that in apoptotic cells and no $\mathrm{AO}$ staining can be observed in stwl ${ }^{\text {UY23 }}$-expressing salivary glands (data not shown). Furthermore, the size of stw/ ${ }^{\text {Y823 }}$-expressing cells (Figure $7 \mathrm{~g}$ and $\mathrm{h}$ ) was sufficient to account for the smaller volume of the gland. Thus, the main effect of stwl in salivary glands is the inhibition of endoreplication.

\section{Discussion}

Stwl is a nuclear protein required for female germline cell development. Its expression is essentially restricted to germline stem cells, nurse cells and the oocyte nucleus until stage 7 of oogenesis. Analyses of loss-of-function phenotypes have suggested that Stwl is required for maintenance of the stem cell pool, or for oocyte differentiation. ${ }^{26,27}$ However, the precise function of Stwl remains unclear. We generated a new allele of stwl, stwl ${ }^{U Y 823}$ by gain-of-function mutagenesis. We show that this allele behaves as a loss-of-function mutation of stwl and that its induction by the UAS/GAL4 system is equivalent to a gain-of-function mutation of stwl. Our results indicate that ectopic expression of the $5^{\prime}$-truncated stwl (stwl $\left.{ }^{U Y 823}\right)$ or the full-length stwl (hsp70-stwl) induces apoptosis and cell proliferation. On the one hand, stw/ UY823 expression in the wing disc increases the number of cells in $\mathrm{S}$ phase, probably by accelerating G1/S transition. On the other hand, stw/ ${ }^{U Y 823}$ expression induces transcriptional activation of the proapoptotic gene rpr. Nevertheless, it has been shown that stwl loss of function induces germ cell apoptosis. ${ }^{26}$ In this case, nurse cells with differentiation defects are eliminated, whereas in the case of stwl ectopic expression overproliferating cells are eliminated. This is consistent with the observation that ectopic stw/ ${ }^{\text {Y823 }}$ expression in the ventral lateral neurons of Drosophila brain induces the death of these cells ( $E$ Blanchardon and $F$ Rouyer, personal communication). We show here that the coexpression of proapoptotic genes (and, to a lesser extent, the coexpression of antiproliferative genes) prevents the pupal death induced by stw/ ${ }^{\text {Y } 823}$ expression at $25^{\circ} \mathrm{C}$. The wing phenotype of survivors was stronger than that observed at $21^{\circ} \mathrm{C}$ for stwl ${ }^{U Y 823}$, and stronger than the phenotype observed when proapototic genes are overexpressed alone. This rescue provides evidence that the pupal death induced by stw/ ${ }^{U Y 823}$ expression results from inappropriate cell proliferation and that triggering the death of overproliferating cells or slowing their proliferation restores viability.

The similarity between the changes induced by ectopic expression of stwl ${ }^{\text {U823 }} \mathrm{stw}^{\text {GS3129 }}$ and hsp70-stwl suggests that these alleles act in a similar manner, in this context. Stwl belongs to the evolutionarily conserved Myb family, and previous studies have shown that $d m y b$ overexpression also induces cell proliferation and apoptosis. As reported here for
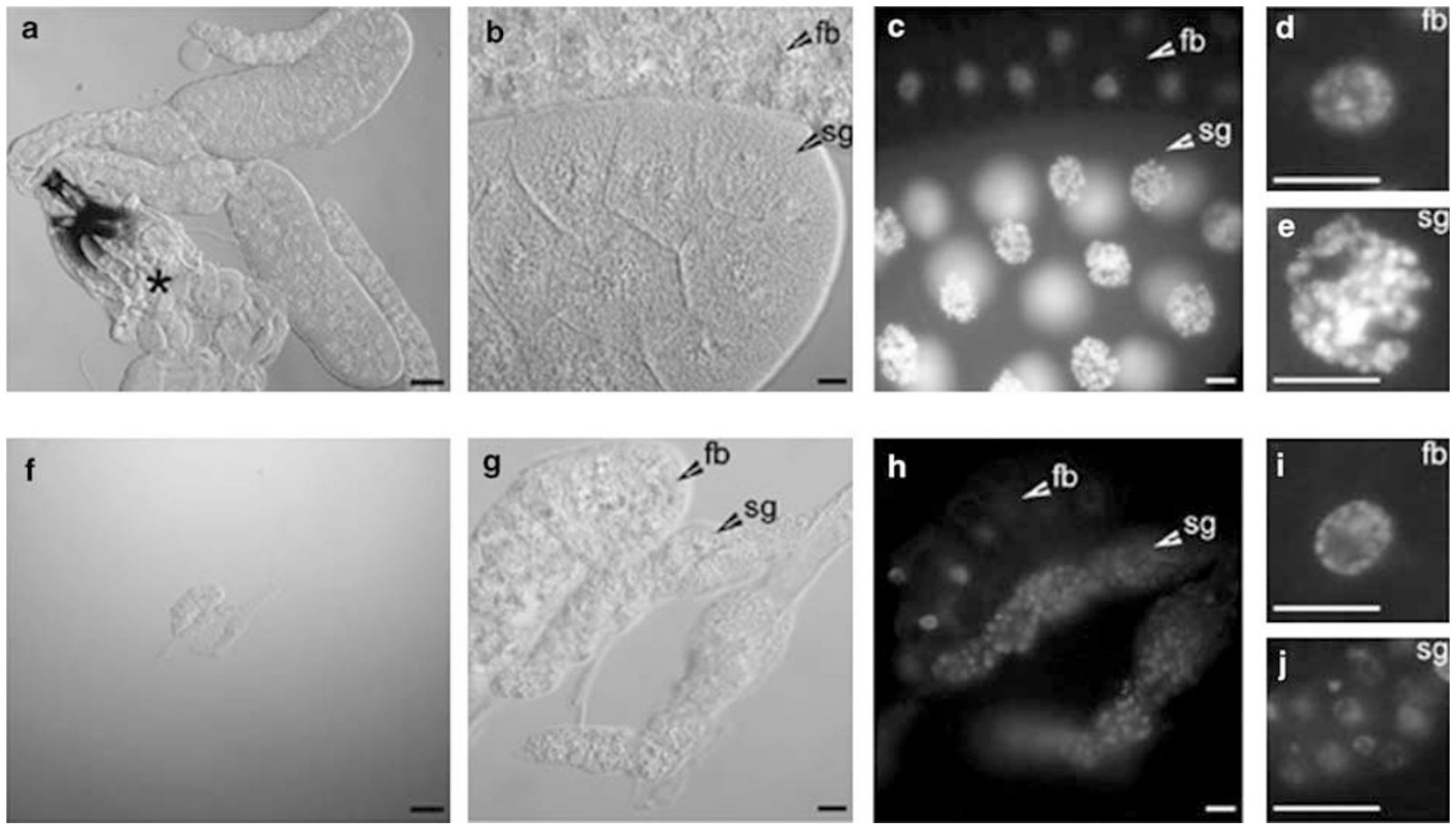

Figure 7 Ectopic expression of $s t w{ }^{U Y 823}$ inhibits endoreplication in salivary glands. Hoechst DNA staining of salivary glands dissected from third instar larvae, carried out on control glands and glands expressing stw/ $\mathrm{V}^{\mathrm{S} 23}$ driven by $f k h-G A L 4$. The endocycling salivary glands are indicated by (sg) and fat bodies by (fb). (a-e) show control glands fkh-GAL4/+. . (f-j) show glands with induced stw/ ${ }^{U Y 823} \mathrm{fkh}-\mathrm{GAL} / \mathrm{stw}^{\mu Y 823}(\mathbf{a}, \mathbf{b}, \mathbf{f}, \mathbf{g})$ are Nomarski images. $(\mathbf{b})$ and $(\mathbf{g})$ are high magnifications of $(\mathbf{a})$ and $(\mathbf{f})$, respectively, and $(\mathbf{c}, \mathbf{h})$ are fluorescence micrographs corresponding to $(\mathbf{b}, \mathbf{g})$. (d, e) and $(\mathbf{i}, \mathbf{j})$ show high magnifications of the nuclei presented in $(\mathbf{c})$ and $(\mathbf{h})$ respectively. (d) and (i) are nuclei from fat bodies and (e) and (j) are nuclei from salivary glands. The scale bar represents $100 \mu \mathrm{m}$ in (a, f) and $20 \mu \mathrm{m}(\mathrm{across})$ in (b-e) and $(\mathbf{g}-\mathbf{j})$. An asterisk indicates mandibles and imaginal discs 
stwl, dmyb expression activates G1/S transition. ${ }^{18}$ Furthermore, stw/ ${ }^{\text {Y } 823}$ expression, like dmyb expression, inhibits endoreplication in salivary glands. It was recently suggested that Stwl may be involved in nuclear inhibition of the cell cycle following DNA damage. ${ }^{32}$ Thus, the expression of $d m y b$ and stwl probably results in the activation of common pathways involved in regulation of the cell cycle and apoptosis.

In conclusion, our results, showing that stwl expression has effects similar to dmyb expression, provide evidence that these genes have conserved functions in the control of cell cycle progression and of apoptosis in Drosophila. Our results also show that stwl activates rpr transcription, consistent with the putative role of Stwl in the response to DNA damage. ${ }^{32}$ Comparisons between $d m y b$ and stwl may make it possible to improve our understanding of the functions of Stwl in germline cells. Our results suggest that Stwl stimulates cell cycle progression, consistent with the requirement to maintain the stem cell pool. Furthermore, Stwl could be involved in inhibiting the endocycling of DNA in the oocyte, which must enter meiosis. By contrast, nurse cells become polyploid. Finally, it would be of interest to screen for suppressors of pupal death due to the $v g$-GAL4-driven expression of stwl ${ }^{\cup Y 823}$ as a means of identifying new genes potentially interacting with stwl.

\section{Materials and Methods}

\section{Fly stocks}

Flies were raised on standard medium. The UAS-GFP, UAS-bax, UASbcl-2, da-GAL4, vg-GAL4, gmr-GAL4/curly of Oster (CyO) and en-GAL4 lines have been described elsewhere., ${ }^{4,5}$ The UAS-rpr and UAS-hid transgenic lines were generated by recombination of the X-linked UAS-rpr, UAS-hid transgenic line described previously. ${ }^{33}$ The rpr-11-lacZ construct was generated by Nordstrom et al. ${ }^{30}$ The stw/ ${ }^{U Y 23}$ and brat ${ }^{U Y 1131}$ lines were generated by mobilizing p\{Mae-UAS.6.11\}. ${ }^{25}$ brat $^{U Y 1131}$ is an inducible allele of the antiproliferative gene brain tumor suppressor (personal communication from M Simonelig). The UAS-grim line was generated by Wing et al. ${ }^{34}$ The UAS-sickle line was generated by Srinivasula et al. ${ }^{35}$ The UAS-pro-dronc line has been described by Quinn et $a{ }^{36}{ }^{36}$ UAS-dredd $\delta$ has been described by Vidal et al. ${ }^{37}$ UAS-rbf was generated by Du et al. ${ }^{38}$ UAS-dacapo was generated by Lane et $a .^{39}$ The $w ; P\left\{w^{+}\right.$, minigene stwl $\}$and $w ; P[h s p 70-s t w l]$ lines were generously provided by D McKearin and were generated by Clark et al. ${ }^{26}$ The GS3129 line was generously provided by $T$ Aigaki, and was generated by gain-offunction mutagenesis, by Toba et al. ${ }^{31}$ The fkh-GAL4 was generously provided by Dr. $S$ Beckendorf. ${ }^{40}$ UAS-p35 $(P\{w[+m C]=U A S-$ p35.H\}BH3, $\left.\left.w^{*}\right]\right), P\{l a c W\} s t w / 6 c 3$ and $P\{U A S-D I A P 1 . H\} 3$, and all the lines required for genetic localization of the UY823 transgene originated from the Bloomington Drosophila Stock Center. The $y, w^{\mathcal{C}}$ and $w^{1118}$ lines were used as control strains.

\section{Northern blot analyses}

For total RNA analysis, 25 hs-GAL4/ + ;stwl $\mathrm{UY}^{\mathrm{S} 23} /+$ males and $25 \mathrm{hs}$ GAL4/+ males raised at $25^{\circ} \mathrm{C}$ were ground in TRIzol (Invitrogen). RNA was extracted according to the manufacturer's instructions. We used $20 \mu \mathrm{g}$ of total RNA for the Northern blot.

For poly $(A)^{+}$RNA analysis, $250 y, w^{C}$ control females and 250 stwl ${ }^{\text {UY823 }}$ homozygous females ( 1 -week-old) raised at $21^{\circ} \mathrm{C}$ on standard medium supplemented with fresh yeast were ground in TRIzol. Total RNA was extracted, and poly $(A)^{+}$RNA was isolated using the MicroFastTrack $^{\mathrm{TM}} 2.0$ Kit (Invitrogen). We used $20 \mu \mathrm{g}$ of poly $(\mathrm{A})^{+}$RNA for the Northern blot.

The stwI DNA probe (1085 bp) was obtained by PCR from the CDNA of stwl cloned in $\mathrm{pBS} \Sigma \mathrm{c} 3.5$ (\#1) (generously provided by $D$ McKearin), using primers $\mathrm{P}^{\text {stwlS2 }}$ (GCCGAGTGAGAACGCCTGGAA) and P4 $4^{\text {stwIR4 }}$ (CTGGCCCGGATGGCGGCTTGT). The rp49 DNA probe (431 bp) was generated by PCR from the CDNA of $r p 49$ (inserted into pGEM-5Zf $(+)$ ) using forward (GTGTATTCCGACCAGGTTACA) and reverse (ATACAGGCCCAAGATCGTGA) primers. The single-stranded DNA probes for stwl and $r p 49$ were radiolabeled with ${ }_{\alpha} \mathrm{P}^{32}$-dCTP by random priming, using the Megaprime RPN1606 Kit (Amersham).

\section{Reverse transcription polymerase chain reaction (RT-PCR) analysis}

For total RNA analysis, 200 en-GAL4/ + ;stw/ ${ }^{U Y 823} /+$ imaginal wing discs and 200 en-GAL4/ + imaginal wing discs of larvae raised at $25^{\circ} \mathrm{C}$ were used. RNA was extracted with the 'SV Total RNA Isolation System' following the manufacturer's instructions (Promega; reference Z3100).

A semiquantitative RT-PCR method was used to determine the levels of $s t w l^{U Y 823}$ mRNA in en $>$ stw/ ${ }^{U Y 823}$ imaginal wing discs. This technique is based on evaluation of the amount of stw/ ${ }^{U Y 823}$ cDNA fragment amplified during the exponential phase of PCR. As a control, rp49 cDNA was amplified in the same PCR tube. Approximately $500 \mathrm{ng}$ of total RNA from en $>$ stwl ${ }^{\text {YY823 }}$ imaginal wing discs was denatured by heating before reverse transcription (RT). RT was performed in the presence of random hexamers, in a total volume of $25 \mu \mathrm{l}$, according to the recommendations of the kit manufacturer (M-MLV, 28025-013, Invitrogen). A 224-bp fragment was amplified from the stw/ ${ }^{U Y 823}$ CDNA sequence, using primer $\mathrm{P}_{1}{ }^{\mathrm{ISA}}$ (CTCTCAACAAGCAAACGTGC), which binds at $-87 \mathrm{bp}$, in the UY $P$ element sequence, and primer P2 ${ }^{\text {stwIR3 }}$ (GTCCATCGGCCAGCGGATAA), which binds at $+3025 \mathrm{bp}$. A 430-bp fragment was amplified from the rp49 CDNA using the primers (GTGTATTCCGACCAGGTTACA) and (ATACAGGCCCAAGATCGTGA). PCR was carried out over 27 cycles ( $30 \mathrm{~s}$ each at 92,64 and $72^{\circ} \mathrm{C}$ ).

\section{Genomic localization of the UY823 transposon}

Genomic DNA was extracted from stw/ ${ }^{U Y 823}$ flies with a standard fly 'miniprep' method, by E Jay Rehm (BDGP). PCR on genomic DNA, using the $\mathrm{P} 1^{\text {ISA }}$ (CTCTCAACAAGCAAACGTGC) and P2 $2^{\text {stwlR3 }}$ (GCTCATCGGC CAGCGGATAA) primers, generated a fragment of about $2900 \mathrm{bp}$. The forward primer used, $\mathrm{P} 1^{1 \mathrm{SA}}$ is specific to the $5^{\prime}$ end of the UY transposon and can be used to amplify the DNA strand transcribed upon UAS/GAL4 induction ( + strand). The reverse primer, $\mathrm{P} 2{ }^{\text {stwIR3 }}$ allows amplification of the noncoding strand of stwl from position +3006 of the coding sequence. Two independent PCR products were then sequenced, using $P 1^{\text {ISA }}$ (MWG Biotech Germany).

\section{Test of phenotype suppression by coexpression of the $p 35$ gene}

We crossed vg-GAL4, UAS-GFP/CyO; stw ${ }^{\text {UY823 }}$ TM3 Drosophila males with UAS-p35/UAS-p35 or $w^{1118}$ females at $21^{\circ} \mathrm{C}$. The progenies of both crosses were counted and classified in different groups according to the number of notches on their wings. Flies with a notch in the anterior part of the wing were also counted. The data were analyzed by means of $\chi^{2}$ tests. 


\section{Viability experiment}

At $12 \mathrm{~h}$ after egg laying, embryos were collected and counted. After $36 \mathrm{~h}$ of development at $25^{\circ} \mathrm{C}$, we counted the dead embryos. We counted pupae and adult flies 6 and 12 days after egg laying (Table 2).

\section{Heat-shock protocol}

Flies of the $w^{1118}$ and $h s p 70$-stwl genotypes were raised at $21^{\circ} \mathrm{C}$. Third instar larvae were placed for $20 \mathrm{~min}$ at $37^{\circ} \mathrm{C}$ and then returned to $21^{\circ} \mathrm{C}$ for a further $20 \mathrm{~min}$. This temperature shift was performed three times, and the larvae were finally placed at $21^{\circ} \mathrm{C}$ and collected $20 \mathrm{~h}$ after the last shock.

\section{Histology}

As stw/ ${ }^{U Y 823}$ expression driven by en-GAL4 is lethal at the late larval or pupal stage, at $21^{\circ} \mathrm{C}$ (data not shown), and stw/ ${ }^{U Y 823}$ expression driven by $v g$-GAL4 is pupal lethal at $25^{\circ} \mathrm{C}$, we dissected and analyzed wing discs of third instar larvae grown at both lethal temperatures, to ensure that the most severe phenotypes were observed.

\section{Detection of $v g-G A L 4$ and en-GAL4 expression in wing discs}

vg-GAL4,UAS-GFP and en-GAL4,UAS-GFP females were crossed with $y, W^{C}$ males and to $s t w /{ }^{U Y 823}$ males. Progeny was raised at $21^{\circ} \mathrm{C}$ for enGAL4 induction and at $25^{\circ} \mathrm{C}$ for $v g-G A L 4$ induction. Third instar larvae in the progeny were dissected in $1 \times \mathrm{PBS}, \mathrm{pH}$ 7.6. Larvae were then fixed in $\mathrm{PBS} / 4 \%$ formaldehyde, washed three times, for $3 \mathrm{~min}$ each in PBS and placed in PBS/glycerol $(1: 1)$ overnight at $4^{\circ} \mathrm{C}$. Discs were then mounted in glycerol and observed with a conventional Leica DMRHC research microscope, using the L5 filter to detect green fluorescence and the Nomarski filter for bright-field micrographs.

\section{AO staining of wing discs}

en-GAL4 females were crossed with stw/ ${ }^{U Y 823}$ males and $v g-G A L 4$ females were crossed with stw/ ${ }^{U Y 823}$ and stw/ ${ }^{G S 3129}$ males. en-GAL4/+; stw $\mathrm{UY}^{\mathrm{Y} 823} /+$ larvae were raised at $21^{\circ} \mathrm{C}, \mathrm{vg}-\mathrm{GAL} 4 /+; \mathrm{stw}^{U Y 823} /+$ and $v g-G A L 4 /+;\left.s t w\right|^{G S 3129} /+$ larvae were raised at $25^{\circ} \mathrm{C}$. Control discs were dissected from en-GAL4/+ and $v g-G A L 4 /+$ larvae. Discs were dissected in $1 \times$ PBS, pH 7.6, and then stained for $2 \mathrm{~min}$ in $100 \mathrm{ng} / \mathrm{ml}$ AO (Molecular Probes), for cell death assessment. Discs were then mounted in PBS and observed with a conventional Leica DMRHC research microscope, using the $\mathrm{I} 3$ filter to detect $\mathrm{AO}$ fluorescence and the Nomarski filter for bright-field micrographs.

\section{X-gal staining of wing discs}

en-GAL4,UAS-GFP females were crossed with rpr-11-lacZ,stwl $^{\text {UY823 }}$ males and with rpr-11-lacZ males for the control. The progeny were raised at $21^{\circ} \mathrm{C}$ and larvae were dissected in $1 \times \mathrm{PBS}$, pH 7.6, on ice. Larvae were fixed in $\mathrm{PBS} / 4 \%$ formaldehyde $/ 1 \%$ glutaraldehyde at $20^{\circ} \mathrm{C}$, washed three times, for $3 \mathrm{~min}$ each in $1 \times \mathrm{PBS}$, stained for $4 \mathrm{~h} 20 \mathrm{~min}$ at $37^{\circ} \mathrm{C}$ in $1 \times$ PBS, $4 \mathrm{mM} \mathrm{K}_{4} \mathrm{Fe}_{2}, 4 \mathrm{mM} \mathrm{K}_{3} \mathrm{Fe}_{3}, 1 \mathrm{mM} \mathrm{MgCl}, 1 \%$ Triton X-100, $800 \mathrm{ng} / \mathrm{ml} \mathrm{X-gal,} \mathrm{washed} \mathrm{twice} \mathrm{for} 3 \mathrm{~min}$ each in PBS, fixed for $5 \mathrm{~min}$ and washed three times, for 3 min each, in $1 \times$ PBS. Discs were then placed in $\mathrm{PBS} /$ glycerol $(1: 1)$ overnight at $4^{\circ} \mathrm{C}$, mounted in glycerol and observed with a conventional Leica DMRHC research microscope, using the Nomarski filter.

\section{BrdU labeling of wing discs}

en-GAL4 females were crossed with stw ${ }^{U Y 823}$ males, and with $y, w^{C}$ males for the control. The progeny were raised at $21^{\circ} \mathrm{C}$, and larvae were fed for $4 \mathrm{~h}$ on medium supplemented with $1 \mathrm{mg} / \mathrm{ml}$ BrdU. Larvae were then dissected in $1 \times$ PBS, pH 7.6, and fixed in PBT/formaldehyde $(1 \times \mathrm{PBS} /$ $4 \%$ formaldehyde $/ 0.3 \%$ Triton $\mathrm{X}-100$ ) for $20 \mathrm{~min}$ at room temperature, washed three times, for 3 min each in PBT, denatured in $2.2 \mathrm{~N} \mathrm{HCl} / 0.1 \%$ Triton X-100 by two incubations, for 15 min each, neutralized with $100 \mathrm{mM}$ sodium tetraborate (Borax) by two incubations, for $5 \mathrm{~min}$ each. For immunohistochemistry, larvae were blocked by incubation in PBT/10\% normal goat serum (NGS) for $45 \mathrm{~min}$, incubated with 1:20 diluted mouse anti-BrdU monoclonal antibody containing nuclease (Amersham, RPN202) overnight at $4^{\circ} \mathrm{C}$ and washed three times, for $20 \mathrm{~min}$ each, in PBT/NGS. Discs were then incubated with 1:1000 diluted Alexa-Fluor488 goat anti-mouse $\lg G$ or with $1: 50$ diluted biotinylated anti-mouse $\lg G$ (Amersham) and washed three times, for $20 \mathrm{~min}$ each, in PBT. For biotinylated anti-mouse IgG (Figure 2), we used the Vectastein Elite $A B C$ Kit (Vector Laboratories) and the DAB substrate kit for peroxidase (Vector Laboratories) for BrdU detection. Discs were mounted in glycerol and observed with a conventional Leica DMRHC research microscope, using the Nomarski filter. For Alexa-Fluor-488 goat anti-mouse IgG (Figure 6), discs were mounted in glycerol and observed with a Leica SP2 right confocal microscope.

\section{DNA staining of salivary glands}

Salivary glands were dissected from third instar larvae, fixed by incubation for $30 \mathrm{~min}$ in paraformaldehyde $4 \%$ and labeled by incubation with $1 \mu \mathrm{g} / \mathrm{ml}$ Hoechst stain at room temperature for $15 \mathrm{~min}$. Images of salivary glands were captured with a conventional Leica DMRHC research microscope, using the A filter to detect Hoechst fluorescence and the Nomarski filter for bright-field micrographs. The same exposure time was used for all images.

\section{Acknowledgements}

We thank E Blanchardon for drawing our attention to the UY823 line, $\mathrm{F}$ Leulier for providing us with the UAS-dredd $\delta$ line, D McKearin, who generously provided us with the stw ${ }^{\Delta 95}$ and the hsp70-stw/ mutant strains, the $P\left\{w^{+}\right.$, minigene stwl $\}$line and the vector containing the stwl cDNA, $S$ Beckendorf, who provided us with the fkh-GAL4 strain, and the Bloomington Drosophila Stock Center for fly stocks. The GS3129 line was a gift from T Aigaki. We also thank I Séminet for performing some of the experiments described in this paper, $\mathrm{P}$ Gandille for technical assistance with confocal microscopy, S Gaumer and $C$ Stenbak for critical reading of the manuscript, and J Sappa (from A Edelman \& Associates) for English rereading. This work was supported in part by grants from the Association pour la Recherche Contre le Cancer (\#3367) and the Ligue Nationale Contre le Cancer. Sylvain Brun held successive fellowships from the Ministère de l'Education Nationale, de l'Enseignement Supérieur et de la Recherche, the Fondation pour la Recherche Médicale and the Association pour la Recherche contre le Cancer.

\section{References}

1. Edgar BA and Orr-Weaver TL (2001) Endoreplication cell cycles: more for less. Cell 105: 297-306

2. Hipfner DR and Cohen SM (2004) Connecting proliferation and apoptosis in development and disease. Nat. Rev. Mol. Cell Biol. 5: 805-815 
3. Abrams JM and White MA (2004) Coordination of cell death and the cell cycle: linking proliferation to death through private and communal couplers. Curr. Opin. Cell Biol. 16: 634-638

4. Gaumer S, Guénal I, Brun S, Théodore L and Mignotte B (2000) Bcl-2 and Bax mammalian regulators of apoptosis are functional in Drosophila. Cell Death Differ. 7: 804-814

5. Brun S, Rincheval V, Gaumer S, Mignotte B and Guénal I (2002) rpr and bax initiate two different apoptotic pathways affecting mitochondria and antagonized by $b c l-2$ in Drosophila. Oncogene 21: 6458-6470

6. Hay BA, Huh JR and Guo M (2004) The genetics of cell death: approaches, insights and opportunities in Drosophila. Nat. Rev. Genet. 5: 911-922

7. Mignotte B, Colin J, Brun S and Guénal I (2005) Apoptosis: the fly point of view. In Apoptosis, Scovassi Al (ed) (Kerala, India: Research Signpost) pp. 169-186 (ISBN: 81-308-0021-7)

8. Brodsky MH, Nordstrom W, Tsang G, Kwan E, Rubin GM and Abrams JM (2000) Drosophila p53 binds a damage response element at the reaper locus. Cell 101: 103-113

9. Sogame N, Kim M and Abrams JM (2003) Drosophila p53 preserves genomic stability by regulating cell death. Proc. Natl. Acad. Sci. USA 100: 4696-46701

10. Morey M, Corominas M and Serras F (2003) DIAP1 suppresses ROS-induced apoptosis caused by impairment of the selD/sps1 homolog in Drosophila. J. Cell Sci. 116: 4597-4604

11. Schumacher B, Hofmann K, Boulton S and Gartner A (2001) The C. elegans homolog of the p53 tumor suppressor is required for DNA damage-induced apoptosis. Curr. Biol. 11: 1722-1727

12. Prober DA and Edgar BA (2000) Ras1 promotes cellular growth in the Drosophila wing. Cell 100: 435-446

13. Bergmann A, Agapite J, McCall K and Steller H (1998) The Drosophila gene hid is a direct molecular target of Ras-dependent survival signaling. Cell 95: 331341

14. Baehrecke EH (2003) miRNAs: micro managers of programmed cell death. Curr. Biol. 13: R473-R475

15. Du W, Xie JE and Dyson N (1996) Ectopic expression of dE2F and dDP induces cell proliferation and death in the Drosophila eye. EMBO J. 15: 3684-3692

16. Pedraza LG, Stewart RA, Li DM and Xu T (2004) Drosophila Src-family kinases function with Csk to regulate cell proliferation and apoptosis. Oncogene 23: 4754-4762

17. Hipfner DR and Cohen SM (2003) The Drosophila sterile-20 kinase slik controls cell proliferation and apoptosis during imaginal disc development. PLoS Biol. 1: E35. (Epub 2003 Nov 2017)

18. Fitzpatrick CA, Sharkov NV, Ramsay G and Katzen AL (2002) Drosophila myb exerts opposing effects on $S$ phase, promoting proliferation and suppressing endoreduplication. Development 129: 4497-4507

19. Secombe J, Pierce SB and Eisenman RN (2004) Myc: a weapon of mass destruction. Cell 117: 153-156

20. Sutcliffe JE, Korenjak M and Brehm A (2003) Tumour suppressors - a fly's perspective. Eur. J. Cancer 39: 1355-1362

21. Harbour JW and Dean DC (2000) Rb function in cell-cycle regulation and apoptosis. Nat. Cell Biol. 2: E65-E67

22. Knudsen KE, Weber E, Arden KC, Cavenee WK, Feramisco JR and Knudsen ES (1999) The retinoblastoma tumor suppressor inhibits cellular proliferation through two distinct mechanisms: inhibition of cell cycle progression and induction of cell death. Oncogene 18: 5239-5245

23. Lemaire C, Godefroy N, Costina-Parvu I, Rincheval V, Renaud F, Trotot P, Bouleau S, Mignotte B and Vayssicre JL (2005) Caspase-9 can antagonize p53-induced apoptosis by generating a p76(Rb) truncated form of $\mathrm{Rb}$. Oncogene 24: 3297-3308

24. Hsieh JK, Chan FS, O'Connor DJ, Mittnacht S, Zhong S and Lu X (1999) RB regulates the stability and the apoptotic function of p53 via MDM2. Mol. Cell. 3 : 181-193

25. Monnier V, Girardot F, Cheret C, Andres $\mathrm{O}$ and Tricoire H (2002) Modulation of oxidative stress resistance in Drosophila melanogaster by gene overexpression. Genesis 34: 76-79

26. Clark KA and McKearin DM (1996) The Drosophila stonewall gene encodes a putative transcription factor essential for germ cell development. Development 122: $937-950$

27. Akiyama $T$ (2002) Mutations of stonewall disrupt the maintenance of female germline stem cells in Drosophila melanogaster. Dev. Growth Differ. 44: 97-102

28. Blanchardon E, Grima B, Klarsfeld A, Chelot E, Hardin PE, Preat T and Rouyer F (2001) Defining the role of Drosophila lateral neurons in the control of circadian rhythms in motor activity and eclosion by targeted genetic ablation and PERIOD protein overexpression. Eur. J. Neurosci. 13: 871-888

29. Baehrecke EH (2002) How death shapes life during development. Nat. Rev. Mol. Cell Biol. 3: 779-787

30. Nordstrom W, Chen P, Steller H and Abrams JM (1996) Activation of the reaper gene during ectopic cell killing in Drosophila. Dev. Biol. 180: 213-226

31. Toba G, Ohsako T, Miyata N, Ohtsuka T, Seong KH and Aigaki T (1999) The gene search system. A method for efficient detection and rapid molecular identification of genes in Drosophila melanogaster. Genetics 151: 725-737

32. de Vries HI, Brunsting JF, Lemstra W, Kampinga HH and Sibon OCM (2003) Identification of stonewall as a novel Drosophila gene involved in DNA damage response. In 43rd Annual Drosophila Research Conference (Chicago: The Genetics Society of America)

33. Zhou L, Schnitzler A, Agapite J, Schwartz LM, Steller H and Nambu JR (1997) Cooperative functions of the reaper and head involution defective genes in the programmed cell death of Drosophila central nervous system midline cells. Proc. Natl. Acad. Sci. USA 94: 5131-5136

34. Wing JP, Zhou L, Schwartz LM and Nambu JR (1998) Distinct cell killing properties of the Drosophila reaper, head involution defective, and grim genes. Cell Death Differ. 5: 930-939

35. Srinivasula SM, Datta P, Kobayashi M, Wu JW, Fujioka M, Hegde R, Zhang Z, Mukattash R, Fernandes-Alnemri T, Shi Y, Jaynes JB and Alnemri ES (2002) sickle, a novel Drosophila death gene in the reaper/hid/grim region, encodes an IAP-inhibitory protein. Curr. Biol. 12: 125-130

36. Quinn LM, Dorstyn L, Mills K, Colussi PA, Chen P, Coombe M, Abrams J, Kumar S and Richardson $\mathrm{H}(2000)$ An essential role for the caspase dronc in developmentally programmed cell death in Drosophila. J. Biol. Chem. 275: 40416-40424

37. Vidal S, Kush RS, Leulier F, Tzou P, Nakamura M and Lemaitre B (2001) Mutations in the Drosophila dTAK1 gene reveal a conserved function for MAPKKKs in the control of rel/NK-kB dependent innate immune responses. Genes Dev. 15: 1900-1912

38. Du W, Vidal M, Xie JE and Dyson N (1996) RBF, a novel RB-related gene that regulates E2F activity and interacts with cyclin E in Drosophila. Genes Dev. 10: 1206-1218

39. Lane ME, Sauer K, Wallace K, Jan YN, Lehner CF and Vaessin H (1996) Dacapo, a cyclin-dependent kinase inhibitor, stops cell proliferation during Drosophila development. Cell 87: 1225-1235

40. Zhou B, Bagri A and Beckendorf SK (2001) Salivary gland determination in Drosophila: a salivary-specific, fork head enhancer integrates spatial pattern and allows fork head autoregulation. Dev. Biol. 237: 54-67

Supplementary Information accompanies the paper on the Cell Death and Differentiation website (http://www.nature.com/cdd) 